Research Article

\title{
Molecular Design of Novel Chemicals for Iron Sulfide Scale Removal
}

\author{
Abdulmujeeb T. Onawole $\mathbb{D}^{1},{ }^{1}$ Ibnelwaleed A. Hussein $\left(\mathbb{D},{ }^{1}\right.$ Hassan I. Nimir $\left(\mathbb{D},{ }^{2}\right.$ \\ Musa E. M. Ahmed, ${ }^{1}$ and Mohammed A. Saad ${ }^{1,3}$ \\ ${ }^{1}$ Gas Processing Center, College of Engineering, P.O. Box 2713, Qatar University, Doha, Qatar \\ ${ }^{2}$ Department of Chemistry \& Earth Sciences, College of Arts and Sciences, Qatar University, Doha, Qatar \\ ${ }^{3}$ Chemical Engineering Department, College of Engineering, P.O. Box 2713, Qatar University, Doha, Qatar
}

Correspondence should be addressed to Ibnelwaleed A. Hussein; ihussein@qu.edu.qa and Hassan I. Nimir; hnimir@qu.edu.qa

Received 2 August 2020; Revised 13 January 2021; Accepted 20 January 2021; Published 8 February 2021

Academic Editor: Sevgi Kolayl

Copyright (C) 2021 Abdulmujeeb T. Onawole et al. This is an open access article distributed under the Creative Commons Attribution License, which permits unrestricted use, distribution, and reproduction in any medium, provided the original work is properly cited.

\begin{abstract}
Scale deposition is a pertinent challenge in the oil and gas industry. Scales formed from iron sulfide are one of the troublous scales, particularly pyrite. Moreover, the use of biodegradable environmentally friendly chemicals reduces the cost compared to the conventional removal process. In this work, the chelating abilities of four novel chemicals, designed using the in silico technique of density functional theory (DFT), are studied as potential iron sulfide scale removers. Only one of the chemicals containing a hydroxamate functional group had a good chelating ability with $\mathrm{Fe}^{2+}$. The chelating strength and ecotoxicological properties of this chemical were compared to diethylenetriaminepentaacetic acid (DTPA), an already established iron sulfide scale remover. The new promising chemical surpassed DTPA in being a safer chemical and having a greater binding affinity to Fe $\mathrm{F}^{2+}$ upon optimization, hence, a better choice. The presence of oxime $(-\mathrm{NHOH})$ and carbonyl $(\mathrm{C}=\mathrm{O})$ moieties in the new chemical showed that the bidentate form of chelation is favored. Moreover, the presence of an intramolecular hydrogen bond enhanced its chelating ability.
\end{abstract}

\section{Introduction}

Scale deposition is a cogent problem facing oil and gas production. Scales formed from iron sulfide are one of the troublous scales, particularly pyrite $[1,2]$. Other types of scales include calcium carbonates and sulfates, barium sulfate, and strontium sulfate. The costs related to scale deposition were estimated to be about 800 million \$US in the United Kingdom, 9 billion \$US in the USA, and 3 billion \$US in Japan while the global cost amounted to about 2.5 trillion \$US $[3,4]$. The reaction of iron and hydrogen sulfide forms the iron sulfide scale. The former occurs in the oil and gas production system including pipes, reservoirs, and wellbore tubular. Hydrogen sulfide, on the other hand, is found in sour gas wells as free gas and sometimes it evolves during the degradation of organic sulfur-containing chemicals due to the presence of sulfate-reducing bacteria $[5,6]$.
Conventional treatments used in iron sulfide scale removal include chemical and mechanical treatments [7]. Nevertheless, the former is preferred over the latter as mechanical treatment frequently exacerbates the situation by leading to more corrosion. On the other hand, chemical treatments involving the use of hydrochloric acid increase the corrosion rate and also produce toxic hydrogen sulfide as a by-product. Chelators have been suggested as a better chemical solution for scale removal [8-12]. Diethylenetriaminepentaacetic acid (DTPA) is one of the effective chelators used for iron sulfide scale removal $[1,2]$. However, there is a need to develop novel biodegradable chelators. Hence, in this work, we design novel chemicals based on the hydroxamate functional group and also the carboxylic functional group present in DTPA.

Siderophores are naturally occurring low molecular weight chelators containing catecholate and hydroxamates 
moieties. They are known to form one of the strongest ironchelating complexes and used by microorganisms to sequester iron [13, 14]. Hydroxamates features the general formula- $\mathrm{R}(\mathrm{C}=\mathrm{O}) \mathrm{NHOH}$, where $\mathrm{R}$ could be an alkyl or aryl group. The $-(\mathrm{C}=\mathrm{O}) \mathrm{NHOH}$ moiety is the key functional group binding to iron and hence has been developed and applied in medicine in treating cardiovascular diseases, metal poisoning, and overload of iron and anticancer and antitumor agents [15-18]. Other applications are extended to corrosion inhibition, mineral floatation, and extraction of toxic metals $[19,20]$. The $-(\mathrm{C}=\mathrm{O}) \mathrm{NHOH}$ can be divided into the carbonyl group $(\mathrm{C}=\mathrm{O})$ and the oxime group $(\mathrm{NH}-\mathrm{OH})$. This enables hydroxamates to act as either a monodentate or bidentate and or/bridging ligand when binding to a metal ion. The configuration depends on whether one of the oxygen atoms (monodentate) or both (bidentate) oxygen atoms in the carbonyl and oxime group are used in bonding. Also, hydroxamates have the ability to form both intra- and interhydrogen-bonds which enhances their chelating ability.

Molecular design methods, particularly density functional theory (DFT), have become a widely used tool in understanding the molecular structure of various molecules, including inorganic chemicals [21,22]. Also, it has been used to design novel chemicals never before synthesized as it saves the cost of trial and error compared to wet labs concerning time and chemicals $[23,24]$. However, despite the applications of hydroxamates, there is a dearth of literature on theoretical studies of hydroxamates, and this is due to the challenge in modeling transition metal complexes $[15,19]$. Nevertheless, DFT has been used in studying transition metal complexes $[25,26]$. Herein, we study four novel chemicals having to contain hydroxamic and carboxylic acid functional groups and analyze their chelating ability to $\mathrm{Fe}^{2+\text {, }}$ which is the state of iron in the pyrite scale. Our previous works which include both experimental [27] and theoretical studies [28] showed that borax is an effective iron sulfide scale dissolution agent. The strong Fe-S bonds in the pyrite $\left(\mathrm{FeS}_{2}\right)$ scale are broken and the sulfur reacts with the potassium ions of borax. This gives rise to free $\mathrm{Fe}^{2+}$ ions which can now be removed with chelating agents. The chelating agents can capture or bind to these free $\mathrm{Fe}^{2+}$ ions and aid in their removal. Hence, the binding affinities, ecotoxicological properties of these novel chemicals, are studied. Moreover, the calculation of the binding affinities of chelating agents to a central metal ion such as $\mathrm{Fe}^{2+}$ using DFT has been found to correlate with their corresponding experimental stability constant $[11,29]$. The electronic-structure properties, such as the electrostatic potential map and frontier molecular orbitals of the most promising chemical, are calculated and overall activity is compared to DTPA, which is a well-known iron sulfide scale remover.

\section{Methodology}

2.1. Designing of Chemicals. The novel chemicals were designed after macrocycles, which have been used as iron chelators $[30,31]$ and DTPA which has been previously studied by our group in previous works as an effective iron sulfide scale remover $[2,10-12,32]$. Table 1 shows the
IUPAC name and the corresponding acronym of the designed novel chemicals. TTCC and TCTN are 12-membered ring macrocycles while CMAT and BOEN were designed based on the triamine scaffold in DTPA. Figure 1 shows a flow chart depicting the road map of the novel chemicals used in this study. The structures (Figure 2) of the designed chemicals show that TCTN and CMAT have carboxylic function groups while TTCC and BOEN are hydroxamates. PubChem database was used to confirm that the chemicals are novel [33]. It is crucial to note that though $\mathrm{Fe}^{2+}$ is a borderline lewis acid, borderline donor groups such as those containing amino groups or aromatic rings with nitrogen atoms such as pyridine are recommended as the right ligands to form complexes with it [34]. Many borderline donor groups have already been studied with $\mathrm{Fe}^{2+}$ [35-37]; hence to ensure the novelty of these chemicals, other groups such as hard bases were explored. Moreover, the combination of hard and borderline donor atoms was considered in the designing of these novel chemicals; this is evident in the structures of TCTN and CMAT (Figure 2). This design was done in order to deduce theoretically which donor groups are preferred for binding between hard and borderline bases.

2.2. Computational Details. Gaussian 09 [38] was employed for all DFT calculations at the B3LYP/ def2TZVP basis set using the polarizable continuum model (PCM) for the solvation [39]. This methodology has been used in our earlier computational studies on iron sulfide scale removal $[10,11,32]$. The vibrational frequencies were also calculated, and it was ensured there was absence of imaginary frequencies which implied that the optimized structures had reached a true minimum. The binding energies between the designed chemicals and the metal iron were calculated using equation (1) from the values of their respective sum of electronic and thermal free energies $\left(\varepsilon_{0}+G_{\text {corr }}\right)$ [40]. The ecotoxicity properties of the designed chemicals were predicted using the ADMETopt web tool [41]. Gauss View version 5.0 [42] and Avogadro version 1.1.1 [43] were used as visualization tools for the optimized structures:

$$
\mathrm{BE}=E_{\mathrm{Fe}-\text { complex }}-E_{\text {compound }}-E_{\mathrm{Fe}} \text {. }
$$

\section{Results and Discussion}

3.1. Binding Affinities of Novel Chemicals. DFT calculation was used to calculate the binding affinity between the designed chemicals and $\mathrm{Fe}^{2+}$ using equation (1). All the chemicals formed coordinated bonds with the central metal ion. TTCC formed a perfect square pyramidal shape while TCTN and CMAT had a trigonal bipyramidal shape and BOEN and a near-octahedral shape forming six coordinated bonds with the central metal ion (Figure 3). However, all the binding energies were highly positive particularly TCTN and CMAT except for BOEN which had a negative value of $-3.354 \mathrm{kcal} / \mathrm{mol}$ for its binding energy (Table 2 ). The values of the binding energies are synonymous with the free energies of the reaction of the complexes studied. The free 
TABLE 1: IUPAC names of designed novel chemicals.

IUPAC name

N1,N4,N7,N10-Tetrahydroxy-1,4,7,10-tetraazacyclododecane-1,4,7,10-tetracarboxamide Acronym

$6,6^{\prime}, 6^{\prime \prime}, 6^{\prime \prime \prime}-((1,4,7,10$-Tetraazacyclododecane-1,4,7,10-tetrayl)tetrakis(ethane-2,1-diyl))tetranicotinic acid TTCC $6,6^{\prime}, 6^{\prime \prime}, 6^{\prime \prime \prime}-(((((5-C a r b o x y p y r i d i n-2-y l)$ methyl)azanediyl)bis(ethane-2,1-diyl))bis(azanetriyl $))$ tetrakis(methylene $))$ tetranicotinic acid 2,2'-((3-(1-(2-(bis(2-(Hydroxyamino)-2-oxoethyl)amino)ethyl)-3-hydroxyureido)propyl)azanediyl)bis(N-hydroxyacetamide)

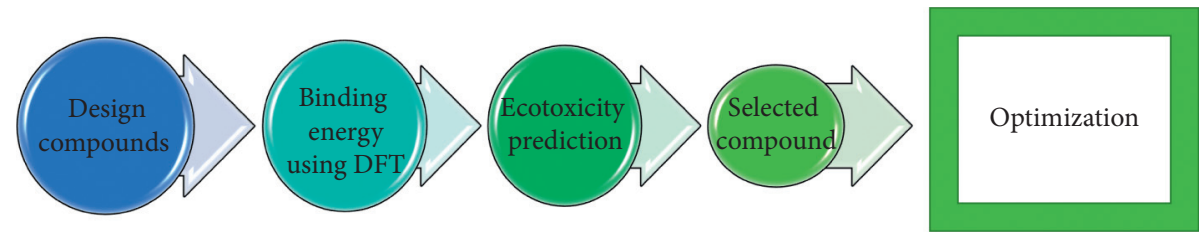

FIgURE 1: Flow chart depicting novel designing of novel chemicals for iron sulfide scale inhibition.<smiles>O=C(NO)N1CCN(C(=O)NO)CCN(C(=O)NO)CCN(C(=O)NO)CC1</smiles>

(a)<smiles>O=C(O)c1ccc(CCN2CCN(CCc3ccc(C(=O)O)cn3)CCN(CCc3ccc(C(=O)O)cn3)CCN(CCc3ccc(C(=O)O)cn3)CC2)nc1</smiles>

(b)<smiles>O=C(O)c1ccc(CN(CCN(Cc2ccc(C(=O)O)cn2)Cc2ccc(C(=O)O)cn2)CCN(Cc2ccc(C(=O)O)cn2)Cc2ccc(C(=O)O)cn2)nc1</smiles>

(c)<smiles>O=C(CN(CCN(CCN(CC(=O)NO)CC(=O)NO)C(=O)NO)CC(=O)NO)NO</smiles>

(d)

Figure 2: Novel chelating agents: (a) TTCC, (b) TCTN, (c) CMAT, and (d) BOEN studied for iron sulfide scale removal.

energies are calculated using the values from the thermal correction to Gibbs free energy from the Gaussian 09 program [38, 40]. This implied that the presence of the aromatic groups reduced the binding capacity of the chemicals as can be seen in Fe-TCTN and Fe-CMAT. This may be due to steric hindrance. However, this very high positive energy is not observed in Fe-TTCC and it is absent in Fe-BOEN, which is the only one that has a good binding affinity among the studied chemicals.
3.2. Ecotoxicity Prediction of Novel Chemicals. Besides the screening of the studied chemicals using their binding affinities to the central metal ion, $\mathrm{Fe}^{2+}$ their ecological toxicity (ecotox) properties were also predicted. This was done to determine how environmentally friendly these chemicals might be. ADMETSAR 2.0 [41, 44] web tool which uses machine learning techniques was used for the ecotox prediction as depicted in Table 3. The SMILES (simplified molecular-input line-entry system) of the studied chemicals 

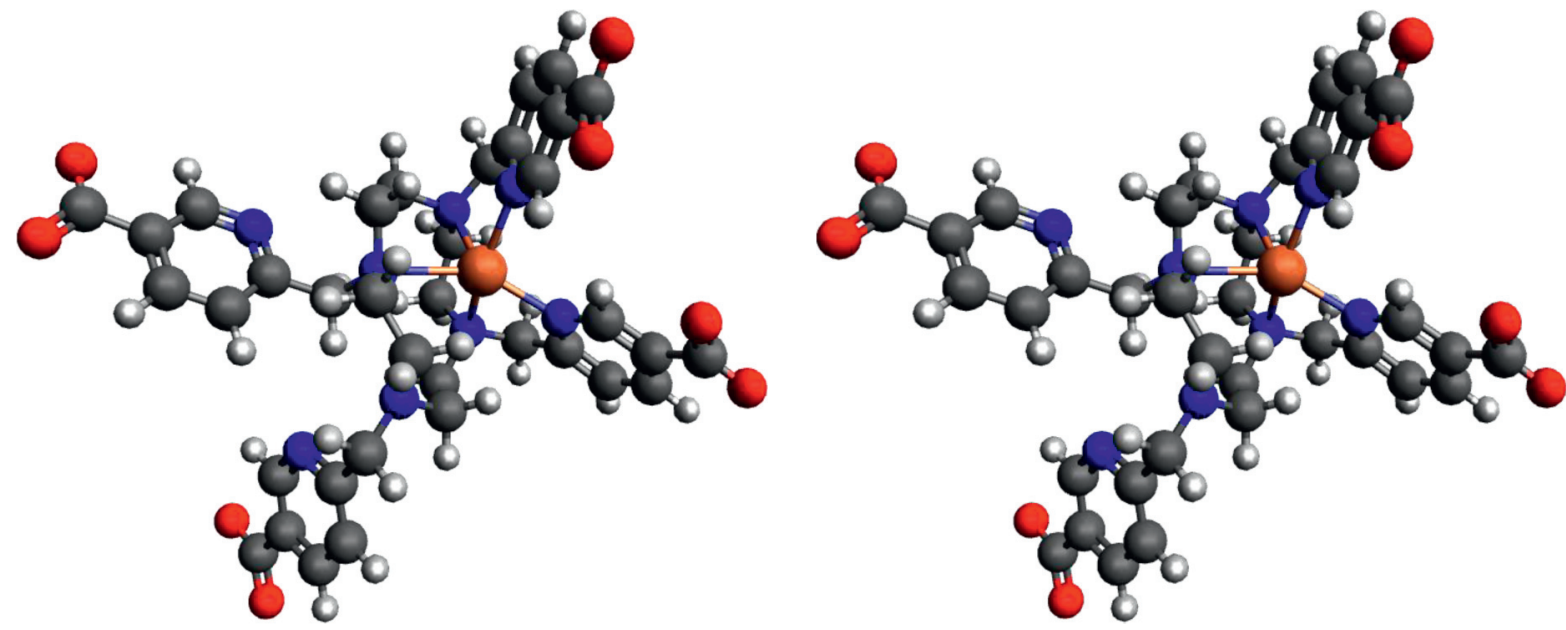

$\begin{array}{ll}\longrightarrow & \mathrm{Fe} \\ \bullet \rightarrow & \mathrm{N} \\ \bullet & \rightarrow \mathrm{C}\end{array}$

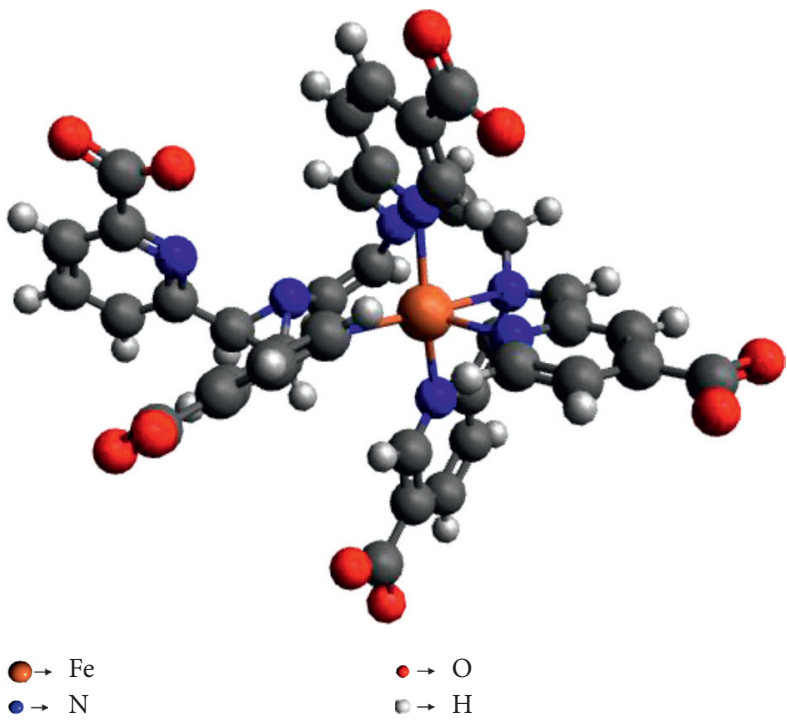

(c)

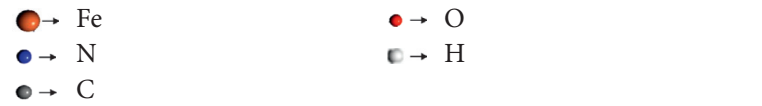

(b)

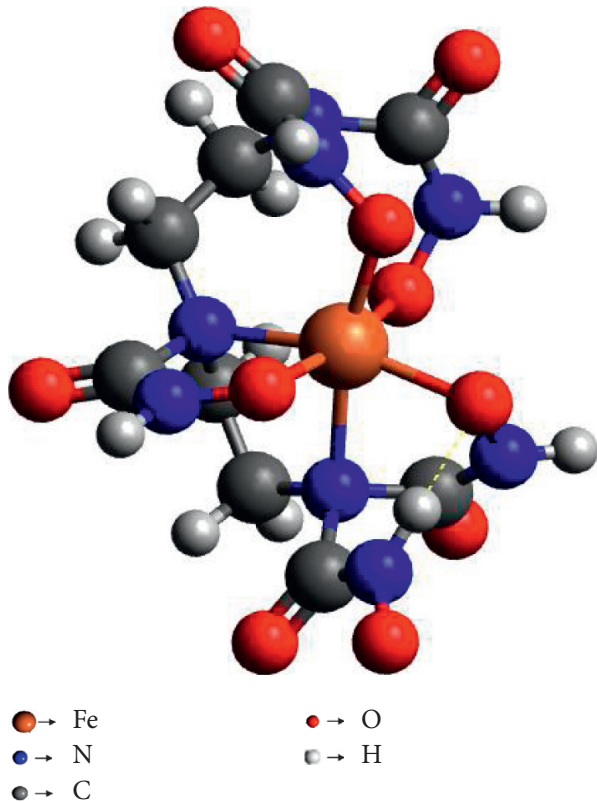

(d)

Figure 3: Complexes of the studied chemicals with $\mathrm{Fe}^{2+}$. (a) Fe-TTCC. (b) Fe-TCTN. (c) Fe-CMAT. (d) Fe-BOEN.

TABLe 2: Calculated binding energies (BE) of the studied novel chemicals.

\begin{tabular}{|c|c|c|c|c|c|c|}
\hline \multicolumn{2}{|c|}{ Complex (kcal/mol) } & \multicolumn{2}{|c|}{ Ligand (kcal/mol) } & \multirow{2}{*}{$\frac{\mathrm{Fe}^{2+}(\mathrm{kcal} / \mathrm{mol})}{-792898.568}$} & \multirow{2}{*}{$\frac{\mathrm{BE}(\mathrm{kcal} / \mathrm{mol})}{782.533}$} & \multirow{2}{*}{$\begin{array}{c}\text { Geometry } \\
\text { Square pyramidal }\end{array}$} \\
\hline Fe-TTCC & -1433116.967 & TTCC & -641000.933 & & & \\
\hline Fe-TCTN & -2320366.446 & TCTN & -1626139.180 & -792898.568 & 98671.302 & Trigonal bipyramidal \\
\hline $\mathrm{Fe}-\mathrm{CMAT}$ & -2482126.589 & CMAT & -1692691.646 & -792898.568 & 3463.625 & Trigonal bipyramidal \\
\hline Fe-BOEN & -1760370.949 & BOEN & -967469.027 & -792898.568 & -3.354 & Near-octahedral \\
\hline
\end{tabular}

was used as the input parameter. The results of only the toxicity properties (ecotox) were considered as other properties such as absorption, distribution, and metabolism (ADME) are irrelevant in this work since its application is not in drug discovery. All the chemicals were safe with respect to carcinogenicity, eye irritation, honey-bee and crustacean toxicity, and biodegradation. However, they were all slightly toxic concerning their acute oral toxicity as they fall into the category of the third class. Chemicals in class IV are nontoxic while those in classes II and I are toxic with 
TABle 3: Predicted ecotoxicity of the studied novel chemicals.

\begin{tabular}{lcccc}
\hline \multirow{2}{*}{ Category } & TTCC & TCTN & CMAT & BOEN \\
& Probability (remark) & Probability (remark) & Probability (remark) & Probability (remark) \\
\hline Carcinogenicity & (Safe) 0.46 & (Safe) 0.66 & (Safe) 0.66 & $($ Safe) 0.46 \\
Eye irritation & (Safe) 0.70 & (Safe) 0.87 & (Safe) 0.89 & (Safe) 0.76 \\
Ames mutagenesis & (Danger) 0.54 & (Safe) 0.74 & (Safe) 0.61 & $($ Safe) 0.64 \\
Acute oral toxicity (class III) & (Caution) 0.57 & (Caution) 0.67 & (Caution) 0.64 & $($ Caution) 0.57 \\
Honey bee toxicity & (Safe) 0.70 & (Safe) 0.80 & (Safe) 0.84 & $($ Safe) 0.68 \\
Biodegradation & (Safe) 0.63 & (Safe) 0.68 & (Safe) 0.83 & (Safe) 0.65 \\
Crustacean aquatic toxicity & (Safe) 0.85 & (Safe) 0.87 & (Safe) 0.6 & $($ Safe) 0.71 \\
Fish aquatic toxicity & (Safe) 0.76 & (Slightly toxic) 0.77 & (Slightly toxic) 0.40 & (Safe) 0.81 \\
Water solubility (logS) & (Insoluble) 2.28 & (Soluble) -3.03 & (Soluble) -2.71 & (Soluble) -2.26 \\
\hline
\end{tabular}

class I being the most toxic $[45,46]$. Only TTCC was found to be mutagenic as it had a 54\% chance of being AMES toxic. TCTN and CMAR were found to be slightly toxic concerning fish toxicity, and this could pose a problem especially if these chemicals were used in offshore production operations. Besides the acute oral toxicity, BOEN has good ecotox properties. Moreover, the category of acute oral toxicity of BOEN is not relevant as these chemicals will not be consumed orally.

3.3. Electronic Structure of the Selected Chemical. The electronic-structure properties which include the electrostatic potential (ESP) and the frontier molecular orbitals maps were calculated for BOEN. The ESP map (Figure 4) denotes the charge distribution highlighting both the electronegative and electropositive regions of the molecule. The ESP decreases in the order of blue, green, yellow, orange, and red where blue denotes the region with the highest electropositivity while red denotes the region with the highest electronegativity [47]. The red region mainly occurs around the hydroxamate moieties especially on the left part of the molecule where three hydroxamate moieties are in close proximity as compared to the other two hydroxamate moieties on the right whose region is between yellow and orange. The overall ESP of the molecule denotes that it is electronegative and this is expected as it will be attracted to a positively charged $\mathrm{Fe}^{2+}$ ion. The highest occupied molecular orbital (HOMO) and lowest unoccupied molecular orbital (LUMO) make up the frontier molecular orbitals (Figures 4(b) and 4(c)) and denote the delocalization of electrons. The HOMO shows the electrons are delocalized all through the molecule except for one hydroxamate moiety on the right. Most of the delocalization occurs at the central hydroxamate moiety. The reverse is observed in the LUMO, where the delocalization can be seen dominant on the hydroxamate moiety on the right and practically absent on the central hydroxamate moiety. These differences may be due to the effect of the $-\mathrm{CH}_{2}-$ groups that occur on both sides of the central hydroxamate moiety while only once in the hydroxamate moiety on the right.

3.4. Optimization of the Selected Chemical. The binding energy of BOEN with one $\mathrm{Fe}^{2+}$ is $-3.354 \mathrm{kcal} / \mathrm{mol}$. However, it was observed that one hydroxamate group was not involved in bonding with the central metal ion (Figure 5(a)). Hence, BOEN was optimized by adding another $\mathrm{Fe}^{2+}$ ion to make it two metal ions bound to BOEN. BOEN was complexed with another $\mathrm{Fe}^{2+}$ ion to see if the free hydroxamates group not participating in forming coordinated bonds with the central $\mathrm{Fe}^{2+}$ ion would be involved in complexation. However, the absence of water molecules hindered the stability of the complex formed. The addition of explicit water molecules is known to improve the stability of complexes [48]. $\mathrm{Fe}^{2+}$ is known to form hexaaquairon that is $\mathrm{Fe}^{2+}\left(\mathrm{H}_{2} \mathrm{O}\right)_{6}$ with a binding energy of $-32.5 \mathrm{kcal} / \mathrm{mol}[49,50]$. However, when complexed with BOEN, the addition of up to 5 explicit water molecules creates a stable square pyramidal shape with each $\mathrm{Fe}^{2+}$ at the central metal ion as depicted in Figures 6(b) and 7(d). Hence, the choice of using five explicit water molecules as larger numbers of water molecules made the complex unstable. Upon the addition of another $\mathrm{Fe}^{2+}$ ion to make it three ions to complex with BOEN, the structure became destabilized. The stability of BOEN with just two $\mathrm{Fe}^{2+}$ ions can be seen that, unlike when complexed with one $\mathrm{Fe}^{2+}$ ion where the chelation is compacted, BOEN stretches and binds with the two central Metal ions at two ends. The addition of another $\mathrm{Fe}^{2+}$ destabilizes this geometry.

This new complex was optimized (Figure 5(b)) and the geometrical parameters of both the optimized structure of BOEN binding to one and two $\mathrm{Fe}^{2+}$ central metal ions were studied (Tables 4 and 5). The binding energy of BOEN to two $\mathrm{Fe}^{2+}$ ions increased from -3.354 to $-340.947 \mathrm{kcal} / \mathrm{mol}$. However, 5 explicit water molecules were included when BOEN was complexed to two $\mathrm{Fe}^{2+}$ ions. These water molecules increased the binding affinity of BOEN with $\mathrm{Fe}^{2+}$ by enabling the formation of a near square pyramidal complex (Figure 5(b)) with each $\mathrm{Fe}^{2+}$ ion forming five coordinated bonds each. The binding energy upon optimization of BOEN was calculated using equation (2). The average Fe-O bond length in the BOEN complex with one $\mathrm{Fe}^{2+}$ ion was longer $(2.035 \AA)$ than in BOEN with two $\mathrm{Fe}^{2+}$ ions $(2.015 \AA)$ as deduced from Tables 4 and 5 . However, there were no Fe-N bonds in BOEN complexed with two $\mathrm{Fe}^{2+}$ ions as they were either bonded to the oxygen of the hydroxamate moiety or the oxygen from the water molecule. The shorter bond length in the latter corroborates the reason why higher binding energy is observed when BOEN binds to two $\mathrm{Fe}^{2+}$ ions. A larger bond angle correlates with a smaller bond length and vice versa and this is observed here. 


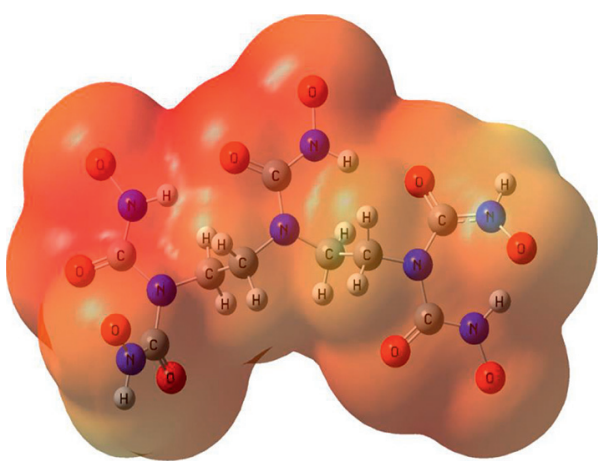

(a)

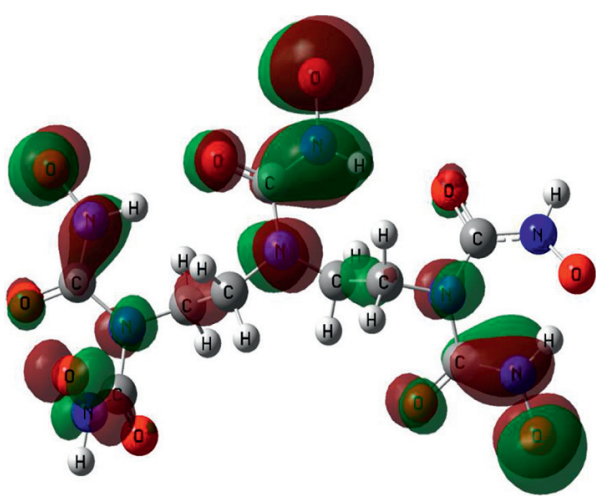

(b)

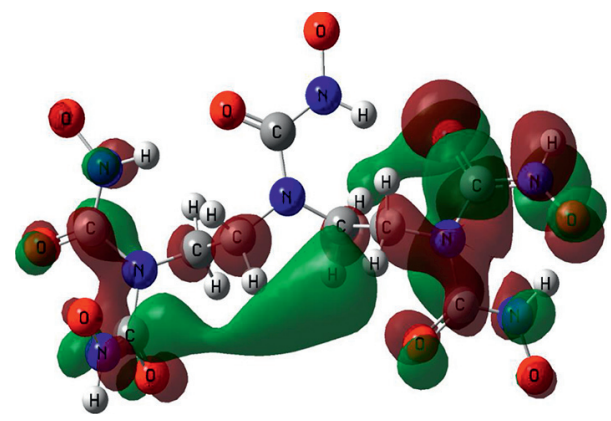

(c)

Figure 4: The (a) ESP, (b) HOMO, and (c) LUMO maps of BOEN.

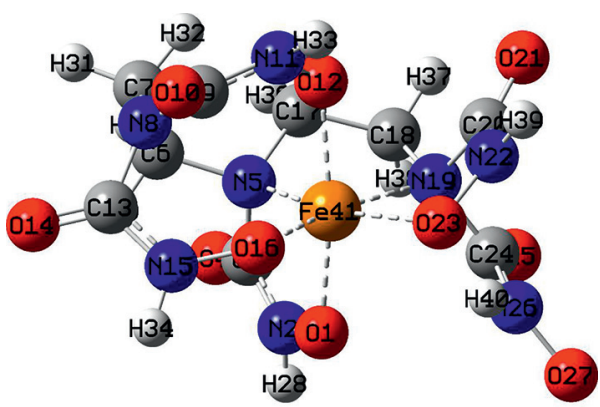

(a)

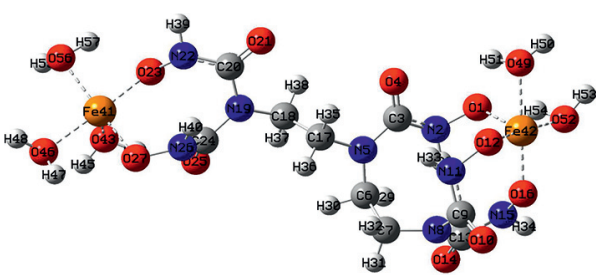

(b)

FIGURE 5: BOEN binding with (a) one and (b) two Fe ions.

To further understand why BOEN had good binding energy to $\mathrm{Fe}^{2+}$ ion compared to the other studied chemicals, the presence of hydrogen bonding was investigated. It has been reported that hydrogen bonding contributes about $1.5 \mathrm{kcal} / \mathrm{mol}$ to binding energy $[45,51]$. BOEN showed the presence of intramolecular hydrogen bonding when complexed with both one $\mathrm{Fe}^{2+}$ and two $\mathrm{Fe}^{2+}$ ions (Figure 6). The hydrogen bond occurred between the hydrogen atom in one hydroxamate moiety and another oxygen atom in another hydroxamate moiety whereas, in BOEN complexed with two $\mathrm{Fe}^{2+}$ ions, the hydrogen bonding occurs between the oxygen atom of the hydroxamate moiety and the hydrogen atom of the water molecules (Figure 6(b)):

$$
\mathrm{BE}=E_{\mathrm{Fe}-\text { complex }}-E_{\text {compound }}-E_{\mathrm{Fe}}-E_{5 \mathrm{H}_{2} \mathrm{O}} .
$$

3.5. Comparison of the Selected Chemical with DTPA. BOEN was compared with DTPA which served as the reference standard. DTPA has been previously studied as an effective iron sulfide scale removal $[8,12]$. The binding energy of DTPA with $\mathrm{Fe}^{2+}$ ion was calculated as $-57.128 \mathrm{kcal} / \mathrm{mol}$ [11] which is higher when compared to BOEN complexed with a single $\mathrm{Fe}^{2+}$ ion $(-3.354 \mathrm{kcal} / \mathrm{mol})$. However, when the binding energy of DTPA complexed with two $\mathrm{Fe}^{2+}$ ions was calculated and compared with BOEN (Figure 7), the former has a binding energy of $-295.193 \mathrm{kcal} /$ mol while BOEN had binding energy of $-340.947 \mathrm{kcal} / \mathrm{mol}$ (Table 6). Upon complexation with two $\mathrm{Fe}^{2+}$ ions and five water molecules, BOEN surpassed DTPA in binding energy. The difference in binding energies is due to the different geometry which both DTPA and BOEN undergo upon 

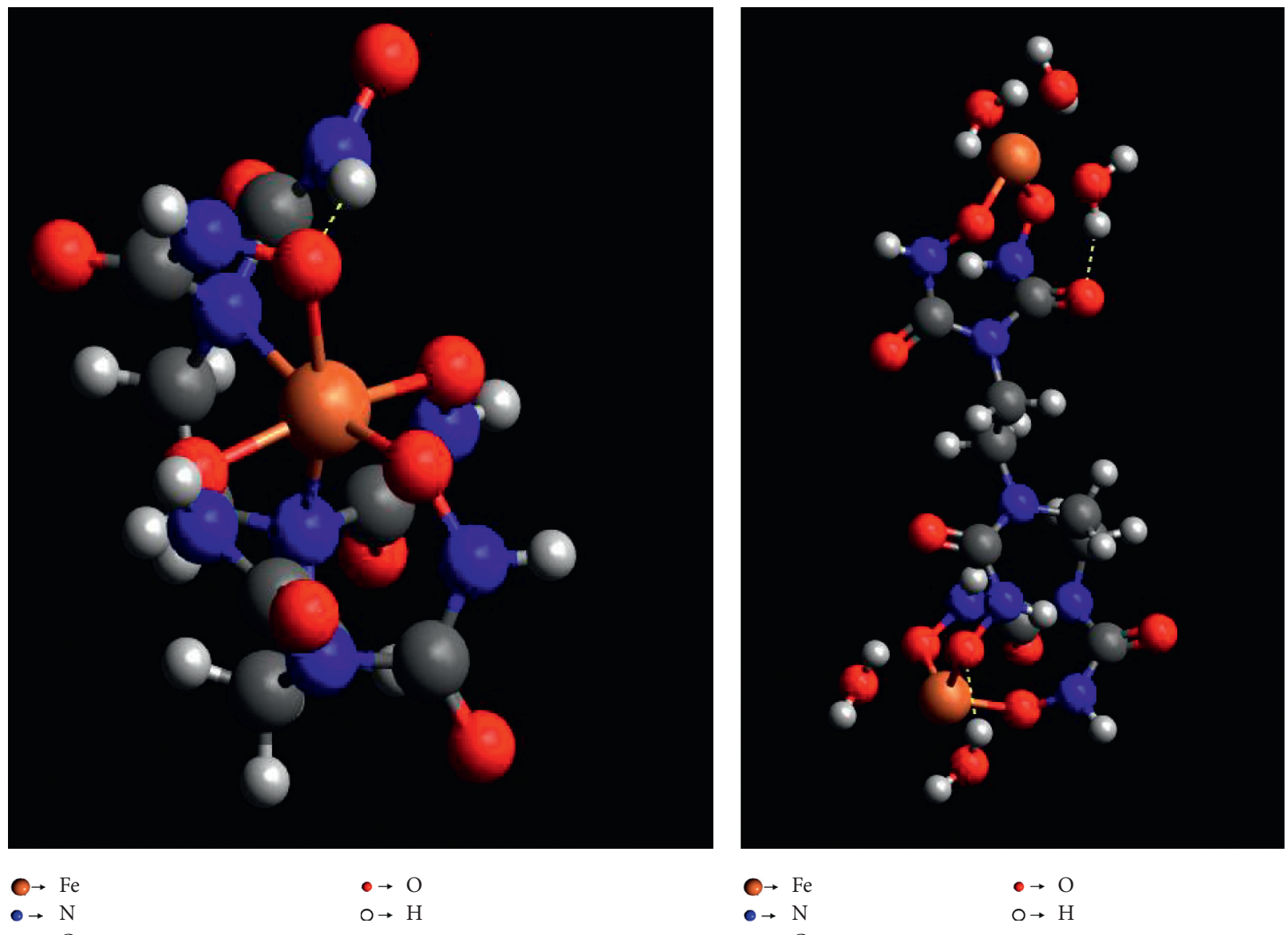

$\rightarrow \mathrm{Fe}$

$$
\leftrightarrow \mathrm{O}
$$

$\rightarrow C$

(a)

(b)

Figure 6: BOEN complexed with (a) one $\mathrm{Fe}^{2+}$ and (b) two $\mathrm{Fe}^{2+}$ ions showing the intrahydrogen bonding in broken yellow lines.

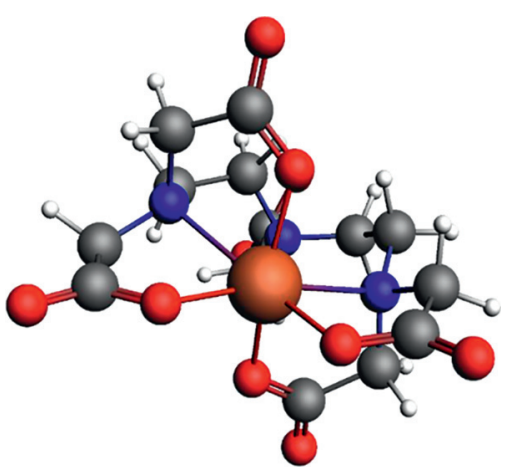

$\mathrm{O} \rightarrow \mathrm{Fe}$
$\bullet \rightarrow \mathrm{N}$
$\bullet \rightarrow \mathrm{C}$

(a)

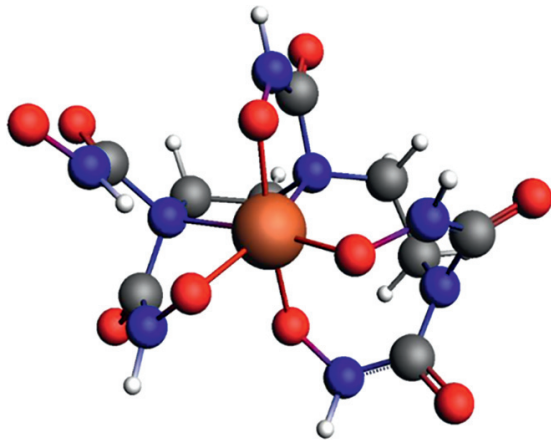

$\rightarrow \mathrm{Fe}$

$\rightarrow \mathrm{N}$

$\rightarrow \mathrm{C}$

(b)

(c)

FIGURE 7: Continued.

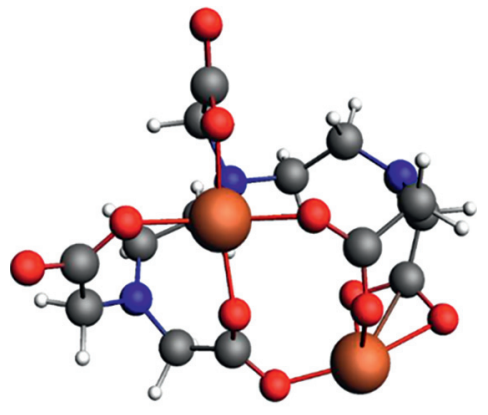

$\begin{array}{ll}\mathrm{O} \rightarrow \mathrm{Fe} & \bullet \rightarrow \mathrm{O} \\ \bullet \rightarrow \mathrm{N} & \bullet \rightarrow \mathrm{H}\end{array}$

$\rightarrow \mathrm{C}$ 


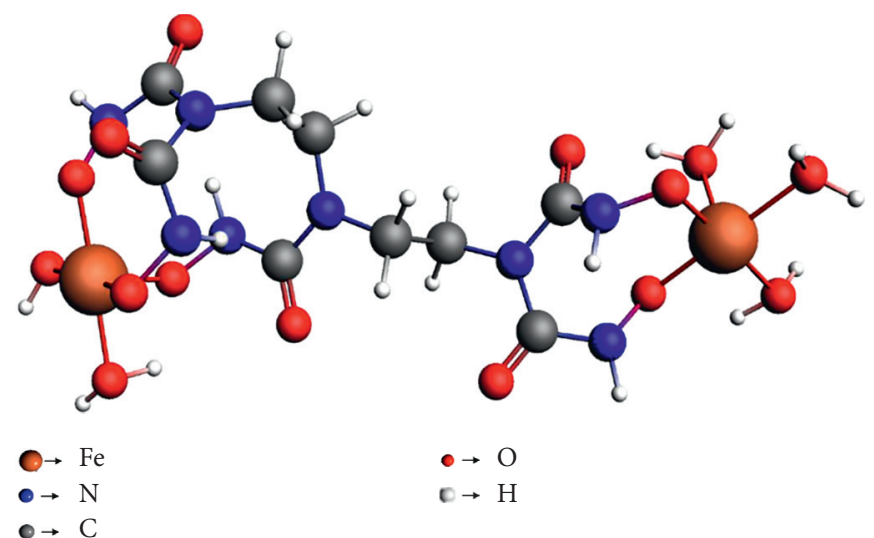

(d)

FIGURE 7: The optimized structures of DTPA complexed with (a) one and (c) two $\mathrm{Fe}^{2+}$ ions and the optimized structure of BOEN complexed, (b) one (d) two $\mathrm{Fe}^{2+}$ ions.

TABLE 4: The bond parameters of BOEN bonded to one $\mathrm{Fe}^{2+}$ ion.

\begin{tabular}{lccc}
\hline Bond & Dist. $(\AA)$ & $<\mathrm{O}-\mathrm{Fe}-\mathrm{O}$ angle & Degrees $\left(^{\circ}\right)$ \\
\hline $\mathrm{Fe}_{41}-\mathrm{O}_{1}$ & 2.008 & $\mathrm{O}_{1}-\mathrm{Fe}_{41}-\mathrm{O}_{16}$ & 89.0 \\
$\mathrm{Fe}_{41}-\mathrm{N}_{5}$ & 2.118 & $\mathrm{O}_{1}-\mathrm{Fe}_{41}-\mathrm{O}_{23}$ & 100.1 \\
$\mathrm{Fe}_{41}-\mathrm{O}_{12}$ & 2.051 & $\mathrm{~N}_{5}-\mathrm{Fe}_{41}-\mathrm{O}_{16}$ & 110.3 \\
$\mathrm{Fe}_{41}-\mathrm{O}_{16}$ & 2.029 & $\mathrm{~N}_{19}-\mathrm{Fe}_{41}-\mathrm{O}_{23}$ & 77.9 \\
$\mathrm{Fe}_{41}-\mathrm{N}_{19}$ & 2.192 & $\mathrm{~N}_{5}-\mathrm{Fe}_{41}-\mathrm{O}_{12}$ & 85.9 \\
$\mathrm{Fe}_{41}-\mathrm{O}_{23}$ & 2.053 & $\mathrm{O}_{12}-\mathrm{Fe}_{41}-\mathrm{N}_{19}$ & 89.5 \\
\hline
\end{tabular}

TABLE 5: The bond parameters of BOEN bonded with two $\mathrm{Fe}^{2+}$ ions.

\begin{tabular}{lclc}
\hline Bond & Dist. $(\AA)$ & $\left.<{ }^{\circ}\right)$ & Degrees $\left(^{\circ}\right)$ \\
\hline $\mathrm{Fe}_{42}-\mathrm{O}_{1}$ & 1.965 & $\mathrm{O}_{46}-\mathrm{Fe}_{41}-\mathrm{O}_{43}$ & 89.6 \\
$\mathrm{Fe}_{42}-\mathrm{O}_{12}$ & 1.936 & $\mathrm{O}_{27}-\mathrm{Fe}_{41}-\mathrm{O}_{46}$ & 83.7 \\
$\mathrm{Fe}_{42}-\mathrm{O}_{16}$ & 1.936 & $\mathrm{O}_{23}-\mathrm{Fe}_{41}-\mathrm{O}_{27}$ & 99.7 \\
$\mathrm{Fe}_{41}-\mathrm{O}_{23}$ & 1.959 & $\mathrm{O}_{46}-\mathrm{Fe}_{41}-\mathrm{O}_{56}$ & 96.6 \\
$\mathrm{Fe}_{41}-\mathrm{O}_{27}$ & 1.930 & $\mathrm{O}_{1}-\mathrm{Fe}_{42}-\mathrm{O}_{49}$ & 78.8 \\
$\mathrm{Fe}_{41}-\mathrm{O}_{43}$ & 2.013 & $\mathrm{O}_{12}-\mathrm{Fe}_{42}-\mathrm{O}_{16}$ & 88.8 \\
$\mathrm{Fe}_{41}-\mathrm{O}_{46}$ & 2.067 & $\mathrm{O}_{49}-\mathrm{Fe}_{42}-\mathrm{O}_{52}$ & 93.3 \\
$\mathrm{Fe}_{41}-\mathrm{O}_{56}$ & 2.080 & $\mathrm{O}_{16}-\mathrm{Fe}_{42}-\mathrm{O}_{52}$ & 83.3 \\
$\mathrm{Fe}_{42}-\mathrm{O}_{49}$ & 2.122 & $\mathrm{O}_{12}-\mathrm{Fe}_{42}-\mathrm{O}_{49}$ & 86.8 \\
$\mathrm{Fe}_{42}-\mathrm{O}_{52}$ & 2.141 & $\mathrm{O}_{1}-\mathrm{Fe}_{42}-\mathrm{O}_{16}$ & 104.9 \\
\hline
\end{tabular}

TABLE 6: Calculated binding energies (BE) of the DTPA and BOEN complexes.

\begin{tabular}{llccccc}
\hline Complex $(\mathrm{kcal} / \mathrm{mol})$ & & \multicolumn{2}{c}{ Ligand $(\mathrm{kcal} / \mathrm{mol})$} & $\mathrm{Fe}^{2+}(\mathrm{kcal} / \mathrm{mol})$ & $5 \mathrm{H}_{2} \mathrm{O}(\mathrm{kcal} / \mathrm{mol})$ & $\mathrm{BE}(\mathrm{kcal} / \mathrm{mol})$ \\
\hline Fe-DTPA & -1710267.251 & \multirow{2}{*}{ DTPA } & -917311.555 & -792898.568 & -239901.357 & -57.128 \\
2Fe-DTPA & -2503038.816 & & & $-1585432.068^{*}$ & -239901.357 & -295.193 \\
Fe-BOEN & -1760370.949 & \multirow{2}{*}{ BOEN } & -967469.027 & -792898.568 & -239901.357 & -3.354 \\
2Fe-BOEN.5H ${ }_{2} \mathrm{O}^{*}$ & -2793143.399 & & & $-1585432.068^{*}$ & -239901.357 & -340.947 \\
\hline
\end{tabular}

${ }^{*} 2 \mathrm{Fe}^{2+}$ ions; energy of $5 \mathrm{H}_{2} \mathrm{O}=-239901.357$.

binding with two $\mathrm{Fe}^{2+}$ ions and the presence of five water molecules in BOEN. These explicit water molecules used in BOEN are not required in DTPA to form a stable complex with good geometry. The ecotoxicity properties of both BOEN and DTPA were also compared (Table 7). BOEN had better ecotoxicological properties concerning carcinogenicity and eye irritation as it was safer than DTPA. The eye irritation predicted for DTPA correlates with what has been reported by the European Chemical Agency which described DTPA as a chemical that causes serious eye irritation [52]. A reaction scheme (Figure 8 ) proposed how BOEN could be synthesized using DTPA as the starting material. This would hopefully help experimental chemists in synthesizing this new chemical. 
TABLe 7: Predicted ecotoxicity of the selected chemical and DTPA.

\begin{tabular}{lcc}
\hline Category & BOEN & DTPA \\
& Probability (remark) & Probability (remark) \\
\hline Carcinogenicity & (Safe) 0.46 & $($ Safe) 0.65 \\
Eye irritation & (Safe) 0.76 & (Irritant) 0.95 \\
Ames mutagenesis & (Safe) 0.64 & (Safe) 0.96 \\
Acute oral toxicity (class III) & (Caution) 0.57 & $($ Caution) 0.81 \\
Honey bee toxicity & (Safe) 0.68 & $($ Safe) 0.62 \\
Biodegradation & (Safe) 0.65 & $($ Safe) 0.50 \\
Crustacean aquatic toxicity & (Safe) 0.71 & $($ Safe) 0.93 \\
Fish aquatic toxicity & (Safe) 0.81 & (Safe) 0.79 \\
Water solubility $(\log )$ & (Soluble) -2.26 & (Soluble) -1.24 \\
\hline
\end{tabular}<smiles>CCOC(=O)CN(CCN(CC(=O)OCC)CC(=O)OCC)CCN(CC(=O)OCC)CC(=O)OCC</smiles>

DTPA

BOEN

FIgURE 8: Proposed reaction scheme of BOEN synthesis from DTPA.

\section{Conclusion}

Iron sulfide scale removal has been a significant challenge in the oil and gas industry during production. Developing effective and green chemicals capable of removing this scale has become pertinent. Herein, four novel chemicals, TTCC, TCTN, CMAT, and BOEN, are designed using in silico method. Their binding energies were 795.56, 98637.83, 3436.95 , and $-3.354 \mathrm{kcal} / \mathrm{mol}$, respectively. All the designed chemicals had poor binding affinities with $\mathrm{Fe}^{2+}$ ion except for BOEN which was the only one which had negative binding energy and hence good binding affinity. The ecological toxicity properties were predicted for the four chemicals of which only BOEN proved to be the safest. The others were predicted to have fish toxicity or were mutagenic. Upon optimization of BOEN by binding it to two $\mathrm{Fe}^{2+}$ ions and adding five explicit water molecules, its binding affinity increased to $-340.947 \mathrm{kcal} / \mathrm{mol}$ which is higher when DTPA is complexed with two $\mathrm{Fe}^{2+}$ ions. The ecotoxicological properties of both DTPA and BOEN were also compared with the latter safer to use than the former. Hence, in both binding affinity and toxicity, BOEN is predicted to be a better choice than DTPA. It was observed that the presence of hydrogen bonding between the hydroxamate moieties and water molecules contributed to the good binding affinity of BOEN. It is important to note that the binding energy of one molecule of DTPA to $\mathrm{Fe}^{2+}(-57.128 \mathrm{kcal} / \mathrm{mol})$ is greater than single $\mathrm{BOEN}$ to $\mathrm{Fe}^{2+}(-3.354 \mathrm{kcal} / \mathrm{mol})$. However upon complexation with two Fe2+ ions, BOEN (-340.947) has a higher binding energy than DTPA $(-295.193 \mathrm{kcal} / \mathrm{mol})$. The reasons for this are the orientation of the BOEN molecule when complexing with two $\mathrm{Fe}^{2+}$ ions and the explicit water molecules present whilst complexing with two $\mathrm{Fe}^{2+}$ ions which are not present when DTPA complexes with two $\mathrm{Fe}^{2+}$ ions. Nevertheless, this work is to provide insight and guide experimental scientist in synthesizing novel green chemicals that can be used for iron sulfide scale removal.

\section{Data Availability}

No data are required to support the study.

\section{Conflicts of Interest}

The authors declare that they have no conflicts of interest.

\section{Acknowledgments}

The authors acknowledge the support of the Qatar National Research Fund (a member of the Qatar Foundation) through Grant no. NPRP9-084-2-041. The discoveries achieved herein are solely the responsibility of the authors. The Research Computing Group at Texas A\&M University at Qatar (funded by Qatar Foundation) provided the HPC facilities used in this work. Qatar University and the Gas Processing Center are also acknowledged for their support.

\section{References}

[1] M. S. Kamal, I. Hussein, M. Mahmoud, A. S. Sultan, and M. A. S. Saad, "Oilfield scale formation and chemical removal: a review," Journal of Petroleum Science and Engineering, vol. 171, pp. 127-139, 2018.

[2] M. Mahmoud, I. A. Hussein, A. Sultan, M. A. Saad, W. Buijs, and T. J. H. Vlugt, "Development of efficient formulation for 
the removal of iron sulphide scale in sour production wells," The Canadian Journal of Chemical Engineering, vol. 96, no. 12, pp. 2526-2533, 2018.

[3] J. Li, M. Tang, Z. Ye, L. Chen, and Y. Zhou, "Scale formation and control in oil and gas fields: a review," Journal of Dispersion Science and Technology, vol. 38, no. 5, pp. 661-670, 2017.

[4] V. S. Saji and S. A. Umoren, Corrosion Inhibitors in the Oil and Gas Industry, Wiley VCH, Weinheim, Germany, 2020.

[5] A. T. Onawole, I. A. Husseinl, M. A. Saad, M. E. M. Ahmed, and H. I. Nimir, "Computational screening of potential inhibitors of desulfobacter postgatei for pyrite scale prevention in oil and gas wells," BioRxiv, Article ID 327957, 2018.

[6] H. Nasr-El-Din and A. Al-Humaidan, "Iron sulfide scale: formation removal and prevention,"in Proceedings of the International Symposium on Oilfield Scale, Society of Petroleum Engineers, Aberdeen, UK, p. 13, January 2001.

[7] A. A. Olajire, "A review of oilfield scale management technology for oil and gas production," Journal of Petroleum Science and Engineering, vol. 135, pp. 723-737, 2015.

[8] M. E. M. Ahmed, M. A. Saad, I. A. Hussein, A. T. Onawole, and M. Mahmoud, "Pyrite scale removal using green formulations for oil and gas applications: reaction kinetics," Energy \& Fuels, vol. 33, no. 5, pp. 4499-4505, 2019.

[9] M. Ahmed, A. Onawole, I. Hussien, M. Saad, M. Mahmoud, and H. Nimir, "Effect of $\mathrm{pH}$ on dissolution of iron sulfide scales using THPS," in Proceedings of the SPE International Conference on Oilfield Chemistry, pp. 1-9, Galveston, TX, USA, April 2019.

[10] A. Onawole, I. Hussein, M. Saad, M. Ahmed, and S. Aparicio, "Application of DFT in iron sulfide scale removal from oil and gas wells," in Proceedings of the Third EAGE WIPIC Workshop: Reservoir Management in Carbonates, Doha, Qatar, November 2019.

[11] A. T. Onawole, I. A. Hussein, A. Sultan, S. Abdel-Azeim, M. Mahmoud, and M. A. Saad, "Molecular and electronic structure elucidation of $\mathrm{Fe}^{2+} / \mathrm{Fe}^{3+}$ complexed chelators used in iron sulphide scale removal in oil and gas wells," The Canadian Journal of Chemical Engineering, vol. 97, no. 7, pp. 2021-2027, 2019.

[12] W. Buijs, I. A. Hussein, M. Mahmoud, A. T. Onawole, M. A. Saad, and G. R. Berdiyorov, "Molecular modeling study toward development of H2S-free removal of iron sulfide scale from oil and gas wells," Industrial \& Engineering Chemistry Research, vol. 57, no. 31, pp. 10095-10104, 2018.

[13] M. Albelda-Berenguer, M. Monachon, and E. Joseph, "Siderophores: from natural roles to potential applications," in Advances in Applied Microbiology, pp. 193-225, Academic Press, Cambridge, MA, USA, 2019.

[14] A. S. Ivanov, B. F. Parker, Z. Zhang et al., "Siderophore-inspired chelator hijacks uranium from aqueous medium," Nature Communications, vol. 10, no. 1, pp. 1-7, 2019.

[15] R. Kakkar, "Theoretical studies on hydroxamic acids," in Hydroxamic Acids. A Unique Family of Chemicals with Multiple Biological Activities, pp. 19-53, Springer, Berlin, Germany, 2013.

[16] R. Martínez, B. Di Geronimo, M. Pastor et al., "Multitarget anticancer agents based on histone deacetylase and protein kinase CK2 inhibitors," Molecules, vol. 25, no. 7, p. 1497, 2020.

[17] R. Arora, U. Issar, and R. Kakkar, "In Silico study of the active site of Helicobacter pylori urease and its inhibition by hydroxamic acids," Journal of Molecular Graphics and Modelling, vol. 83, pp. 64-73, 2018.
[18] S. Kaviani, M. Izadyar, and M. R. Housaindokht, "DFT investigation on the selective complexation of $\mathrm{Fe}^{3+}$ and $\mathrm{Al}^{3+}$ with hydroxypyridinones used for treatment of the aluminium and iron overload diseases," Journal of Molecular Graphics and Modelling, vol. 80, pp. 182-189, 2018.

[19] S. P. Gupta, Hydroxamic Acids: A Unique Family of Chemicals with Multiple Biological Activities, Springer, Berlin, Germany, 2013.

[20] R. Cerón-Camacho, R. Cisneros-Dévora, J.-M. MartínezMagadán et al., "Quantum molecular design and experimental testing of a high-performance zwitterionic corrosion inhibitor for oxidized iron surfaces," Journal of Molecular Graphics and Modelling, vol. 93, Article ID 107444, 2019.

[21] H. Misral, S. Sapari, T. Rahman, N. Ibrahim, B. M. Yamin, and S. A. Hasbullah, "Evaluation of novel N-(Dibenzylcarbamothioyl)benzamide derivatives as antibacterial agents by using DFT and drug-likeness assessment," Journal of Chemistry, vol. 2018, Article ID 9176280, 5 pages, 2018.

[22] I. Mantasha, M. Shahid, M. Kumar et al., "Exploring solvent dependent catecholase activity in transition metal complexes: an experimental and theoretical approach," New Journal of Chemistry, vol. 44, pp. 1371-1388, 2020.

[23] E. C. Herrmann and R. Franke, "Computer aided drug design in industrial Research," in Ernst Schering Research Foundation Workshop 15 Springer, Berlin, Germany, 2013.

[24] R. Castañeda-Arriaga, A. Pérez-González, M. Reina, and A. Galano, "Computer-designed melatonin derivatives: potent peroxyl radical scavengers with no pro-oxidant behavior," Theoretical Chemistry Accounts, vol. 139, no. 8, p. 133, 2020.

[25] M. S. A. Abdel-Mottaleb and E. H. Ismail, "Transition metal complexes of mixed bioligands: synthesis, characterization, DFT modeling, and applications," Journal of Chemistry, vol. 2019, Article ID 3241061, 18 pages, 2019.

[26] M. Gruden and M. Zlatar, "What is the nature of bonding in $\left[\mathrm{Fe}(\mathrm{CO})_{3}(\mathrm{NO})\right]-$ and $\left[\mathrm{Fe}(\mathrm{CO})_{4}\right] 2-$ ?" Theoretical Chemistry Accounts, vol. 139, no. 7, p. 126, 2020.

[27] M. Ahmed, I. A. Hussein, A. T. Onawole, and M. A. Saad, "Development of a new borax-based formulation for the removal of pyrite scales," ACS Omega, vol. 5, no. 24, pp. 14308-14315, 2020.

[28] A. T. Onawole, I. A. Hussein, M. E. M. Ahmed, M. A. Saad, and S. Aparicio, "Ab Initio molecular dynamics of the dissolution of oilfield pyrite scale using borax," Journal of Molecular Liquids, vol. 302, pp. 1-10, 2020.

[29] A. E. Martell and R. M. Smith, Critical Stability Constants, Springer, New York, NY, USA, 1982.

[30] D. G. Workman, M. Hunter, L. G. Dover, and D. Tétard, "Synthesis of novel Iron(III) chelators based on triaza macrocycle backbone and 1-hydroxy-2(H)-pyridin-2-one coordinating groups and their evaluation as antimicrobial agents," Journal of Inorganic Biochemistry, vol. 160, pp. 49-58, 2016.

[31] V. L. Goedken, P. H. Merrell, and D. H. Busch, "Complexes of iron(II) and iron(III) with the tetradentate macrocycle 5,7,7,12,14,14-hexamethyl-1,4,8,11-tetraazacyclotetradeca4,11-diene," Journal of the American Chemical Society, vol. 94, no. 10, pp. 3397-3405, 1972.

[32] A. T. Onawole, I. A. Hussein, M. A. Saad, M. Mahmoud, M. E. M. Ahmed, and H. I. Nimir, "Effect of $\mathrm{pH}$ on acidic and basic chelating agents used in the removal of iron sulfide scales: a computational study," Journal of Petroleum Science and Engineering, vol. 178, pp. 649-654, 2019. 
[33] S. Kim, P. A. Thiessen, E. E. Bolton et al., "PubChem substance and compound databases," Nucleic Acids Research, vol. 44, no. D1, pp. D1202-D1213, 2016.

[34] J. I. Padrón and V. S. Martín, "Catalysis by means of Fe-based lewis acids," Iron Catalysis, vol. 33, pp. 1-26, 2011.

[35] A. Dreab, M. I. Brewer, and C. A. Bayse, "DFT modeling of the prevention of $\mathrm{Fe}(\mathrm{II})$-mediated redox damage by imidazolebased thiones and selones," Journal of Inorganic Biochemistry, vol. 193, pp. 9-14, 2019.

[36] M. A. Ortuño and C. J. Cramer, "Multireference electronic structures of Fe-Pyridine(diimine) complexes over multiple oxidation states," The Journal of Physical Chemistry A, vol. 121, no. 31, pp. 5932-5939, 2017.

[37] R. L. Bruening and K. E. Krakowiak, "Polyamide-containing ligating agents bonded to inorganic and organic polymeric supports and methods of using the same for removing and concentrating desired metal ions from solutions," 2003, https://patents.google.com/patent/US6506706B1/en.

[38] M. J. Frisch, G. W. Trucks, H. B. Schlegel et al., Gaussian 09, Revision D.01, Gaussian, Inc., Wallingford, UK, 2013.

[39] A. V. Marenich, C. J. Cramer, and D. G. Truhlar, "Universal solvation model based on solute electron density and on a continuum model of the solvent defined by the bulk dielectric constant and atomic surface tensions," The Journal of Physical Chemistry B, vol. 113, no. 18, pp. 6378-6396, 2009.

[40] J. W. Ochterski, "Thermochemistry in Gaussian," Gaussian Inc, vol. 1, pp. 1-19, 2000.

[41] H. Yang, L. Sun, Z. Wang, W. Li, G. Liu, and Y. Tang, "ADMETopt: a web server for ADMET optimization in drug design via scaffold hopping," Journal of Chemical Information and Modeling, vol. 58, no. 10, p. 2051, 2018.

[42] T. K. R. Dennington, J. Millam, R. Dennington, and T. Keith, J. Millam, GaussView, Semichem Inc., Shawnee, KS, USA, 2009.

[43] M. D. Hanwell, D. E. Curtis, D. C. Lonie, T. Vandermeersch, E. Zurek, and G. R. Hutchison, "Avogadro: an advanced semantic chemical editor, visualization, and analysis platform," Journal of Cheminformatics, vol. 4, no. 1, p. 17, 2012.

[44] H. Yang, C. Lou, L. Sun et al., "AdmetSAR 2.0: web-service for prediction and optimization of chemical ADMET properties," Bioinformatics, vol. 35, no. 6, pp. 1067-1069, 2019.

[45] K. O. Sulaiman, T. U. Kolapo, A. T. Onawole, M. A. Islam, R. O. Adegoke, and S. O. Badmus, "Molecular dynamics and combined docking studies for the identification of Zaire Ebola Virus inhibitors," Journal of Biomolecular Structure and Dynamics, vol. 37, no. 12, pp. 3029-3040, 2019.

[46] X. Li, L. Chen, F. Cheng et al., "In silico prediction of chemical acute oral toxicity using multi-classification methods," Journal of Chemical Information and Modeling, vol. 54, no. 4, pp. 1061-1069, 2014.

[47] K. O. Sulaiman, A. T. Onawole, D. T. Shuaib, and T. A. Saleh, "Quantum chemical approach for chemiluminescence characteristics of di-substituted luminol derivatives in polar solvents," Journal of Molecular Liquids, vol. 279, pp. 146-153, 2019.

[48] D. E. Bacelo and R. C. Binning, "DFT comparison of $\mathrm{Fe}^{2+}$ hydration in the binding sites of the ferroxidase center of bullfrog M ferritin," The Journal of Physical Chemistry A, vol. 113, no. 7, pp. 1189-1198, 2009.

[49] L. Guimarães, H. A. de Abreu, and H. A. Duarte, "Fe(II) hydrolysis in aqueous solution: a DFT study," Chemical Physics, vol. 333, no. 1, pp. 10-17, 2007.

[50] A. A. Jarzecki, A. D. Anbar, and T. G. Spiro, "DFT analysis of $\mathrm{Fe}\left(\mathrm{H}_{2} \mathrm{O}\right) 63+$ and $\mathrm{Fe}\left(\mathrm{H}_{2} \mathrm{O}\right) 62+$ structure and vibrations; implications for isotope fractionation," The Journal of Physical Chemistry A, vol. 108, pp. 2726-2732, 2004.

[51] E. Stevens, Medicinal Chemistry: The Modern Drug Discovery Process, Pearson Education, Inc., Boston, MA, USA, 2014.

[52] European Chemicals Agency, Opinion of the Committee for Risk Assessment on a Dossier Proposing Harmonised Classification and Labelling at EU Level, European Chemicals Agency, Helsinki, Finland, 2017, https://echa.europa.eu/ documents/10162/7e0bcab6-9ad5-1c24-6002-70cdc1651590. 